\title{
SOCIAL DISTANCES OF WHITES TO RACIAL OR ETHNIC MINORITIES ${ }^{\prime}$
}

\author{
Nina Michalikova \\ Texas Woman's University \\ Philip Q. Yang \\ Texas Woman's University
}

Social distance has been studied by researchers since Emory Bogardus (1925) first developed the social distance scale almost nine decades ago. Social distance refers to "the grades and degrees of understanding and intimacy which characterize pre-social and social relations generally" (Park 1924). As social distance increases, people tend to distance themselves from members of another racial or ethnic group or exclude them from their lives (Yancey 2003). An examination of social distances between different racial or ethnic groups in the United States can help better understand racial and ethnic relations, conflict, cooperation, and alliance.

Previous research on social distance almost exclusively focuses on the social distance between blacks and whites. Results are mixed. Often based on indirect measures of social distance, many studies suggest that the social distance of whites to African Americans has decreased over time, even though ethnic prejudice has not vanished (e.g., Firebaugh and Davis 1988; Schuman et al. 1997; Steeh and Schuman 1992). Today whites are more willing to live in the same neighborhood with African Americans, to accept interracial marriage, to report having a black person as a close friend, and to vote for a black president (Alba, Rumbaut, and Marotz 2005; Healey 2004; Jaynes and Williams 2000; Ladd 2002; Yancey 1999). Findings from existing studies indicate improvements in school and residential integration of blacks. For example, the percentage of whites who object to sending their children to schools where the majority of students were black decreased from 67 percent in 1958 to 34 percent in 1990; the percentage of whites who would definitely move out if blacks moved into their neighborhood in great numbers also declined from 50 percent in 1958 to 18 percent in 1990 (Schuman et al. 1997). Steeh and Schuman (1992) reported that over the last 25 years, white adults "have become steadily more supportive of black advancement on

1 An early version of this paper was presented at the 2009 Annual Conference of the National Association for Ethnic Studies in San Diego, April 2009. 
most, although not all, issues" (340). However, "thermometer ratings," a direct measure of social distance developed by Schuman et al. (1997), contradicts claims that whites' social distance to blacks has gradually decreased. In Schuman et al.'s study, whites were asked to place African Americans on a scale from 0 to 100, indicating how "warm" or "cool" they feel toward them. Interestingly, scores about blacks have hardly varied over the past forty years. "The rating in 1964, when whites were first asked to rate blacks, was sixty, and in 1994 it was sixty-one" (Schuman et al. 1997: 187).

Despite the substantial increase in Hispanic and Asian populations in the United States, there is little research on social distances of whites to Hispanics or Asians. Consequently, there exists basically no direct evidence of social distances between whites and these two groups. A lack of knowledge about the social positions of non-black minorities prevents a fuller understanding of the social positions of not only non-blacks but also blacks (Yancey 2003).

Furthermore, there is a paucity of comparative analysis on the relative order of whites' social distances to racial or ethnic minorities using direct measures of social distance. Existing studies seem to point to the greatest social distance between whites and blacks. For instance, Yancey (2003) argued that "the possibility of assimilation, or a thinning of their racial identity, is stronger for Hispanic Americans and Asian Americans than for African Americans" (83). Blacks experience less assimilation "much more likely due to external rejection than to any internal preference for segregation" (Yancey 2003: 80). Studies of residential segregation (e.g., Massey and Denton 1987, 1993) have consistently found that black-white residential segregation is the highest, followed by Hispanicwhite, and Asian-white segregation. Additionally, the composition of Asians and Hispanics in neighborhoods does not matter much to whites, but African American composition matters (Emerson, Chai and Yancey 2001). Statistics on interracial marriage suggest that whites tend to oppose marrying blacks, but are less concerned about marrying Asians or Hispanics (Yancey 2003). However, these existing studies do not employ a direct measure of social distance.

Additionally, there is inadequate research on what types of whites tend to keep a greater or smaller social distance to minority groups. Whites "differ significantly in the ways that they think about and act toward these racial others" (Feagin and O'Brien 2004: 96). Socioeconomic status, region of residence, age, gender, and personal experience with a particular minority group are often identified or hypothesized as markers of whites associated with their social distances to minorities. Some studies maintain that white Southerners, older whites, and whites who have less contact with minority groups tend to be more prejudiced 
and maintain a greater social distance to minorities (Brink and Harris 1966; Campbell 1971; Feagin and O'Brien 2004; Jaynes and Williams 2000; Schuman et al. 1997; Tuch and Martin 1997). But the effects of some other factors, such as gender and income, are less clear. There are other predictors of social distance that have not been explored.

In an effort to expand the existing literature, this study examines the relative order in social distances of whites to African Americans, Asian Americans, and Hispanic Americans by investigating how white Americans feel toward these three minority groups. The study attempts to answer two research questions: First, what are the differences between whites and major racial or ethnic minorities including African Americans, Asian Americans, and Hispanic Americans in social distance? Second, what kinds of whites are more likely to maintain a greater or smaller social distance to the three minority groups?

The next section reviews theoretical perspectives on group differences in social distance and proposes hypotheses to be tested. The description of the data and methods follows. Finally, results will be presented and discussed.

\section{Theoretical Background And Hypotheses}

Several theoretical perspectives are relevant to our understanding of social distances between whites and racial or ethnic minority groups. The assimilation theory proposed by Robert E. Park (1937), as well as its variant by Milton Gordon (1964), suggests that racial/ethnic relations go through progressive and irreversible cycles, eventually leading to the assimilation of minority groups into the mainstream culture and the disappearance of cultural and ethnic differences. As a result of diminished ethnic cultures, social distances of whites to racial and ethnic minorities should also decrease and eventually disappear.

The cultural pluralism perspective suggests relative equality between groups. Two distinct cultures are not expected to merge as assimilation theories predict, but rather remain distinct and coexistent (Yancey 2003; Yang 2000). This theory assumes that minority groups will preserve their own traditions, languages, customs, and lifestyles, while also sharing a number of traits with the dominant group (Herring and Amissah 1997; Patchen 1999; Yang 2000). According to this perspective, there should be no clear preferences by whites. Social distances between whites and all racial minority groups should be similar, and members of the dominant group supposedly feel favorably toward all minorities. Both the assimilation and cultural pluralism perspectives suggest that social distances of whites to minority groups either do not exist or are insignificant. 
On the contrary, some theories argue for the inevitable existence of social distances of whites to racial or ethnic minority groups. The theory of caste system is one example. This theory analogizes race relations in the United States - especially relations between whites and blacks - to relations between different castes in India (Beteille 1990). Merton (1941) asserted that African Americans occupy the lowest social position and represent the lowest racial caste. European Americans, on the other hand, occupy the highest social position and constitute the highest racial caste. Along the line of the caste system perspective, Healey (2004) pointed to a great stability in rankings of different groups by whites. For decades, rankings remain as follows: groups from Northern and Western Europe tend to be ranked by whites as the highest, followed by groups from Southern and Eastern Europe, with other racial or ethnic minorities situated close to the bottom of the hierarchy. Similarly, James Geschwender (1978) introduced the "color-gradient" system. He stated that lighter-skinned groups are ranked higher and experience far less discrimination than members of darker-skinned groups. The color-gradient theory acknowledges the existence of social distances. In this study, Asian Americans are perceived as having lighter skin than Hispanics. Therefore, according to the system of color-gradient, whites should maintain the least social distance to Asians, followed by Hispanics and blacks.

Conflict theories are also pertinent to the analysis of social distance. These theories are based on the premise that "economic forces are at the root of ethnic antagonisms" (Herring and Amissah 1997: 125), suggesting that relations between different racial and ethnic groups are determined by subordination, exploitation, and resource inequalities (Herring and Amissah 1997). Conflict theories imply that social distances between whites and minority groups are greater than those between minority groups themselves. Furthermore, whites supposedly reject all minority groups and vice versa. Another perspective to consider is the alienation thesis. Glazer (1993) argued that assimilation does not happen equally for all groups, especially not for African Americans. Statistics of intermarriage and residential or school segregation support Glazer's claim that compared to Hispanics and Asians, blacks remain the least assimilated minority group. As a result, African Americans might be more alienated by the dominant group than other racial and ethnic groups. Similarly, according to Yancey (2003), the alienation suffered by African Americans is of a different level than alienation suffered by Hispanics and Asians. As a result, African Americans are destined to remain an "outcast race" (Yancey 2003: 13). The alienation thesis recognizes the existence of social distances and would predict smaller social dis- 
tances between whites and non-black racial minorities and a greater social distance between whites and blacks.

Rejecting the order-oriented theories and following the line of the conflict-oriented theories, we argue that social distances exist between whites and racial or ethnic minorities. Specifically, we hypothesize that whites feel "coolest" toward African Americans, "warmest" toward Asian Americans, and somewhat "warm" toward Hispanics. This hypothesis is based on several considerations. One consideration is the prevailing group image. Whites often refer to Asian Americans as "a model minority" (Takaki 1989), which despite all prejudices and discrimination succeeds economically, socially, and educationally (Schaeffer 2010). This attitude supposedly contributes to a smaller social distance of whites to Asians. Feagin and O'Brien (2004) asserted that whites often associate Asian Americans with intelligence and education and deem both Asian and Hispanic Americans as hard workers. This also indirectly implies smaller social distances between these two groups and whites, compared to blacks. In contrast, whites' negative perceptions of African Americans tend to prevail, especially when it comes to socioeconomic success (Bobo, Kluegel and Smith 1997). Whites tend to think of blacks as "less intelligent, more violence prone, lazier, less patriotic, and more likely to prefer living off welfare than whites" (Bobo and Kluegel 1997: 118). Some researchers have concluded that while blacks are likely to be open to interaction with other groups, "the desire for social distance from African Americans is generally greater than the desire for social distance from virtually all other groups on virtually all fronts" (Herring and Amissah 1997: 142).

Group conflict is another consideration. Historically, group conflict between whites and blacks has been the most severe. Blacks were the only minority group enslaved, and extensive discrimination against them continued even after slavery was abolished. Frequently, white-black conflict is elevated to violent confrontation. Examples from the past are lynching of blacks by whites after the Civil War and Reconstruction, riots of white workers against blacks, or hostile sentiments through hate speeches by Ku Klux Klan (Yang 2000). As a consequence of historical events, there might be greater tension in the present relationship between whites and blacks than between whites and Asians or Hispanics. Ethnic conflict between whites and these latter two groups has been somehow less severe.

Furthermore, group differences in socioeconomic status can account for variations in social distance. Based on the 2000 Population Census, Asian Americans fared better in terms of all socio-economic indicators than both Hispanics and blacks. Asians tended to have a higher level of education (U.S. Census Bureau 2003a), a higher occupational status 
(U.S. Census Bureau 2003b), a higher income (U.S. Census Bureau 2005), and a lower poverty and unemployment rate (U.S. Census Bureau 2003c). All of these reduce the social distance of whites to Asians.

The initial contact situation between different racial groups might have an influence on present social distances. Blauner (1972) distinguished between "most colonized" and "most immigrant" minorities. This perspective proposes that initial contact can have an impact on the contemporary situation of a particular group, with most colonized minorities currently having a more disadvantageous situation. According to Blauner's theory, Asians and Hispanics among the most immigrant minorities, and blacks are among the most colonized minorities, which could also account for the greater social distance between whites and blacks.

What kinds of whites are more likely to have a greater or smaller social distance to minority groups? We expect that whites with a higher socioeconomic status, such as a higher education, a higher occupational prestige score, and a higher family income, tend to maintain a smaller social distance with the minorities than whites with a lower socioeconomic status. According to Campbell (1971), intellectual growth contributes to more positive racial attitudes. Similarly, Noel (1971) argued that a higher education level is associated with a more liberal way of thinking. Weil (1985) pointed to the consistency of research in reporting the positive relationship between higher educational attainment and social or political tolerance. Schuman et al. (1997) found that education of whites has a significant effect on promoting liberal racial attitudes. If more educated whites are on average more liberal, they also might be less prejudiced and more likely to accept people of different races or ethnicities. Therefore, we hypothesize that more educated whites tend to maintain a smaller social distance with minorities than less educated whites. The higher level of education results in a better job and a higher occupational prestige. Therefore, the effect of occupational prestige on whites' social distances to minorities is anticipated to be the same as that of education.

Existing research presents inconclusive results regarding the effect of income on social distance. Campbell (1971) found very little variation in racial attitudes of whites with different income levels. According to Schuman et al. (1997), the impact of income level on racial attitudes toward blacks might vary with the kind of questions asked. For example, "higher income is positively related to willingness to vote for a black candidate, but it is negatively related to support for special programs to advance the economic position of blacks" (1997: 230). Assuming that higher income is associated with higher education, and higher education 
with more liberal attitudes, it is anticipated that income is inversely related to the social distance of whites to minorities.

Some demographic characteristics of whites are expected to have an influence on social distances. One of these characteristics is gender. Few studies examined the effect of gender on racial attitudes. For example, Schuman et al. (1997) found that white women tend to be less conservative on most racial policy issues than white men, with the exception of more intimate racial contact, such as intermarriage or support for schools where the majority of students are black. Johnson and Marini (1998) concluded that white women are more likely to approve of interracial contact and consider it more desirable than white men. Therefore, it is anticipated that white men maintain a greater social distance from minorities than their female counterparts.

Self-employed whites are more likely to face competition from minority business owners than white employees. Asian Americans tend to be successful small-business owners (Schaefer 2010). The success of self-employed Asians presents potential economic competition with selfemployed whites. According to Bobo and Hutchings (1996), in terms of economic and job competition, whites feel the most threatened by Asians, and the least by blacks. This leads to the expectation of a greater social distance between self-employed whites and minorities than that between white employees and minorities.

Noel (1971) argued that white Southerners are less liberal in their racial attitudes because their racial socialization is different from socialization of white non-Southerners. Middleton (1976) stated that in the 1960s, residents of the South were more prejudiced against blacks than those living in other regions, regardless of their psychological characteristics, socioeconomic status, and the degree of urbanization or ethnic composition of the region. According to Wilson (1996), the gap in racial and ethnic prejudice between Southern whites and whites in other regions has narrowed over time, but regional differences in white attitudes remain. The West, the Northeast, and to a lesser extent the Midwest, are more liberal than the South. Tuch and Martin (1997) found that Southern whites "are the least likely to endorse policies intended to ameliorate racial inequality" (1997: 173). This leads to our expectation that Southern whites tend to maintain greater social distances from minorities than whites living in other regions.

Protestantism, the most prevalent religion in the United States, reflects beliefs of the dominant group, which normally do not favor racial and ethnic differences. This is reflected by the religious affiliation of major racial and ethnic groups. With the exception of blacks, minorities tend to prefer religions other than dominant Protestantism. Hispanics are largely Catholics and Asians tend to be associated with Eastern religions. 
Hence, we expect that white Protestants are more likely to have a greater social distance from minorities than white non-Protestants.

Whites born in the United States do not share immigration and naturalization experience with many Asians, Hispanics, and blacks who were born abroad. In addition, native-born whites tend to claim as just American, and they either lack an ethnic identity or practice symbolic ethnicity (Gans 1979; Waters 1990). As a result, they may be less sensitive to the diverse racial and ethnic backgrounds of minorities. In contrast, foreignborn whites are more likely to retain their ethnicity and practice their ethnic cultures. Thus, we hypothesize that U.S.-born whites maintain a greater social distance to minorities than foreign-born whites.

The Republican Party is often perceived as less favorable toward minorities on several social issues. Blacks largely identify with the Democratic Party, as do Hispanics, with the exception of Cubans. In the 1990s, Asians were more or less evenly divided between the Republican Party and the Democratic Party (Nakanishi 1991), but their political affiliation is currently shifting more toward the Democratic Party. Based on these political orientations, it is expected that white Republicans tend to maintain a greater social distance to minorities than white nonRepublicans.

We hypothesize that younger generations of whites are more likely to maintain a smaller social distance to African Americans, Asian Americans, and Hispanic Americans than earlier generations of whites. This pattern assumes progressive trends and a gradual decline in social distances of whites to all minorities over time (Schuman et al. 1997). Researchers often point to progress in racial attitudes of whites toward blacks (Campbell 1971; Firebaugh and Davis 1988; Schuman et al. 1997). Limited evidence exists in support of liberalization of whites' racial attitudes toward Asians and Hispanics. However, according to Wilson (1996), social distances of whites to these two minorities are also declining. While it is expected that whites' social distances to all minorities have decreased, the rates might vary across different groups. The decline in whites' social distance to blacks may be smaller than that to Asians or Hispanics.

\section{Data ANd Methods}

\section{Sample}

Data from the 2002 General Social Survey (GSS) are used to test the proposed hypotheses, because the 2002 GSS is the only sample that contains information on social distances of whites to minorities. The analysis is restricted to white respondents only because the study focuses on social distances of white Americans to racial or ethnic minorities. In addition, only the respondents who provided valid responses to the de- 
pendent variables on feelings toward racial/ethnic minorities (discussed below) are selected for analysis. The data were weighted so that only one adult per household was included in the sample. After the restrictions, the sample size is 1,851 for all three dependent variables.

The data set used in this analysis has several advantages. The 2002 GSS is a nationally representative sample of U.S. non-institutionalized, adult population aged 18 or over, and it allows for the generalization of findings to the U.S. population. To our knowledge, no other recent nationally representative sample provides information on social distances of whites to minorities, which makes this sample unique. In addition, it includes many demographic, socioeconomic, and attitudinal variables. The large sample size permits the use of many explanatory variables and insures the reliability of statistical estimates.

Despite these merits of our sample, some limitations should be acknowledged. Social distance can be measured by different indicators, but our sample only contains measures related to feelings toward racial or ethnic groups. Another limitation is the unavailability of some variables in this particular year, such as variables measuring direct contact between white Americans and minorities. These limitations notwithstanding, this large representative sample remains the best data set available to study social distances between white Americans and racial or ethnic minorities.

\section{Variables and Measurements}

Variables used in the analysis are summarized in Table 1. Means and standard deviations of the variables are included. Medians are included for ordinal variables. The three dependent variables used in this study are 9-point scale measures, indicating the differences in feelings of white Americans toward racial and ethnic minority groups (1 indicates feeling "warmest", and 9 feeling "coolest"). The dependent variables are based on the following three questions: "In general, how warm or cool do you feel toward African Americans?", "In general, how warm or cool do you feel toward Asian Americans?", and "In general, how warm or cool do you feel toward Hispanics?" No question about feelings toward Native Americans or Native Hawaiian or other Pacific Islanders was asked in the GSS data; hence, we cannot examine feelings of whites toward these minority groups in this study.

Previous research indicates that most independent variables used in this study directly influence social distance. Several demographic variables are included in the analysis. Sex is a dummy variable with 1 indicating male and 0 female. Similarly, religion is a dummy variable with 1 for the designated category Protestant and 0 for the reference category non-Protestant. We used a set of dummy variables for region of respon- 


\section{TABLE 1}

Descriptive Statistics of Variables Used in the Analysis, White Americans Aged 18 or OVer, 2002 GSS

\begin{tabular}{lccr}
\hline Variable & Mean & Median & S.D. \\
\hline Dependent Variables & & & \\
Feelings toward African Americans (9-point scale) & 3.62 & 4 & 1.96 \\
Feelings toward Asian Americans (9-point scale) & 3.67 & 4 & 1.96 \\
Feelings toward Hispanic Americans (9-point scale) & 3.59 & 4 & 2.01 \\
Independent Variables & & & \\
Male & 0.48 & - & 0.50 \\
U.S. born & 0.93 & - & 0.25 \\
Self-employed & 0.12 & - & 0.33 \\
Protestant & 0.51 & - & 0.50 \\
Republican & 0.34 & & 0.47 \\
Region & & - & 0.46 \\
$\quad$ South & 0.31 & - & 0.44 \\
$\quad$ Northeast & 0.27 & - & 0.40 \\
Midwest & 0.21 & - & 0.41 \\
$\quad$ West & 0.21 & 13.59 & 2.90 \\
Years of schooling & 44.49 & 44.00 & 13.85 \\
Occupational prestige score & 17.20 & 18.00 & 5.01 \\
Family income (23-point scale) & & & \\
Generation & 0.14 & - & 0.34 \\
$\quad$ G.I. Generation & 0.11 & - & 0.32 \\
Silent Generation & 0.39 & - & 0.49 \\
$\quad$ Baby Boomers & 0.23 & - & 0.42 \\
$\quad$ Generation X & 0.13 & - & 0.33 \\
$\quad$ Generation Y & & & \\
\hline
\end{tabular}

S.D. - Standard Deviation

dents' residence - Northeast, West, and Midwest, with South as the reference category. Country of birth is dummy coded 1 for born in the United States and 0 for born outside the country. Socioeconomic characteristics are represented by the variables education, occupational prestige, and total family income. Education is measured by years of schooling. Family income is measured by a 23-point scale, with income under $\$ 1,000$ as the lowest category and income of $\$ 110,000$ or over as the highest. Occupational prestige score is a 100-point scale with a higher score indicating a higher prestige of respondents' occupation. We used self-employment status as a measure of entrepreneurship and potential economic competition, and this variable is dummy coded 1 for the selfemployed and 0 for employees. Political party affiliation is also a dummy variable with 1 indicating Republican and 0 non-Republican. Finally, to measure generational differences in social distance, we created a set of dummy variables for generations using the cohort variable. The G.I. Generation is the oldest in the sample, including individuals born in 1936 or earlier, and is used as the reference category. The Silent Generation includes individuals born between 1937 and 1945. The Baby Boomers 
include individuals born between 1946 and 1964. The Generation X includes individuals born between 1965 and 1976. The Generation Y includes individuals born since 1977 (Jones and Fox 2009).

\section{Methods and analytical strategies}

We first compared the means of the three dependent variables to see how whites felt differently toward the three minority groups. We then did a correlational analysis to examine the initial relationships between the predictor variables and the dependent variables. Finally, we conducted an ordinary least squares regression (OLS) analysis. The emphasis of this analysis is to compare the constants of the regression models in order to ascertain the differences in whites' feeling toward the three minority groups controlling for all predictors and to test what types of whites are more or less likely to have cooler feelings toward Asians, Hispanics and blacks. The OLS regression model is appropriate since the dependent variables, albeit ordinal, have a large number of categories (9).

\section{RESUlts}

\section{Descriptive and Bivariate Analysis}

As shown in Table 1, the means of the dependent variables indicate that on the 9-point scale, white respondents felt coolest toward Asians (3.67), followed by blacks (3.62) and Hispanics (3.59). These results contradict what was expected, but the differences are small. Standard deviations for the dependent variables vary between 1.96 and 2.01, indicating lower variation of scores in feelings of whites toward Asians and blacks and greater variation in whites' feelings toward Hispanics. Since the median scores are higher than the means in all three measures, the distribution of all dependent variables is somewhat negatively skewed, with few extremely low scores indicating very warm feelings of whites. Possible effects of skewness were tested by creating a scatterplot and by log-transforming the dependent variables, but no significant impact on regression results was detected.

The mean of a dummy variable can be interpreted as a percentage after multiplying it by 100 . Table 1 shows that there were a lower proportion of males (about 48 percent) than females. An overwhelming majority of them (93 percent) were born in the United States. Most of the respondents were employees, and about 12 percent were self-employed. The majority of the respondents (51 percent) were Protestants. About one third considered themselves to be Republican. About 31 percent of all respondents lived in the South, about 21 percent lived in the West and the Midwest respectively, and 27 percent resided in the Northeast. The respondents on average had above 14 years of schooling. The average 
occupational prestige score was approximately 45 on the 100-point scale. The mean for family income was about 17 , meaning that on average respondents' family income was between $\$ 35,000$ and $\$ 39,999$. Baby Boomers (39 percent) constituted the largest generation compared to other generations.

Table 2 shows the bivariate correlations between all pairs of variables used in the analysis. The three dependent variables are correlated with one another highly, suggesting that whites had very similar feelings toward racial or ethnic minorities. The significant positive correlations between the male dummy variable and all three dependent variables indicate that white men tended to feel cooler toward all three minority groups, especially blacks, than white women. Whites living in the West were less likely to feel cooler toward minorities than those living in other parts of the country, but there was no significant difference between whites in the Northeast and those living elsewhere. Whites in the Midwest felt cooler toward Hispanics than whites in other regions, but not toward other groups. The difference between white Republicans and white non-Republicans was not significant. As anticipated, white Protestants tended to feel cooler toward minorities than their non-Protestant counterparts. Native-born whites felt cooler toward Hispanics than foreign-born whites, but not toward other groups. Consistent with our hypotheses, education, occupational prestige, and family income all reduced negative feelings toward all three minority groups. Self-employment increased negative feelings toward Asians and blacks, but not toward Hispanics. There was no significant difference between whites of the Silent Generation or white Baby Boomers and other generations in feelings toward minorities. Whites of Generation $\mathrm{X}$ tended to feel significantly warmer toward Asians and Hispanics, but not toward blacks. In addition, whites who belonged to Generation Y harbored less cool feelings toward Asians and blacks than other generations. The results indicate no multicollinearity problem.

\section{Multivariate Analysis}

For each dependent variable, we tested a number of nested regression models. Based on the comparison of coefficients of determination $\left(\mathrm{R}^{2}\right)$, the model incorporating all explanatory variables (the full model) was determined to be the best fitting model for all three groups. Because of the space constraints and for more effective presentation, only results of the best fitting model are presented (Table 3).

To assess the overall feelings of whites toward the three minority groups, we compared constants of the full regression model for Asians, Hispanics, and blacks presented in Table 3 . The results indicate that, controlling for all explanatory variables, whites felt warmest toward Hispan- 
TABLE 2

Correlation Matrix for Variables Used in the Analysis, White Americans Aged 18 or Over, 2002

\begin{tabular}{|c|c|c|c|c|c|c|c|c|c|}
\hline & $\begin{array}{l}\text { Feelings } \\
\text { about } \\
\text { Asians }\end{array}$ & $\begin{array}{l}\text { Feelings } \\
\text { about } \\
\text { Hispanics }\end{array}$ & $\begin{array}{l}\text { Feelings } \\
\text { about } \\
\text { Blacks }\end{array}$ & Male & Midwest & West & Northeast & Republican & Protestant \\
\hline Feelings about Asians & 1.000 & $.794 * *$ & $.783 * *$ & $.104^{* *}$ & .014 & $-.081^{* *}$ & -.015 & .001 & $.063 * *$ \\
\hline Feelings about Hispanics & --- & 1.000 & $.746^{* *}$ & $.115^{* *}$ & $.047^{*}$ & $-.097 * *$ & -.031 & .020 & $.077 * *$ \\
\hline Feelings about Blacks & --- & --- & 1.000 & $.161^{* *}$ & .037 & $-.064 * *$ & -.038 & .028 & $.053^{*}$ \\
\hline Male & --- & --- & --- & 1.000 & .014 & -.028 & -.009 & .043 & -.008 \\
\hline Midwest & --- & --- & --- & --- & 1.000 & $-.262 * *$ & $-.307 * *$ & $-.085^{* *}$ & $-.200 * *$ \\
\hline West & --- & --- & --- & --- & --- & 1.000 & $-.318^{* *}$ & -.021 & $-.104 * *$ \\
\hline Northeast & --- & --- & --- & --- & --- & --- & 1.000 & -.023 & .037 \\
\hline Republican & --- & --- & --- & --- & --- & --- & --- & 1.000 & $.192 * *$ \\
\hline Protestant & --- & --- & --- & --- & --- & --- & --- & --- & --- \\
\hline Born U.S. & --- & --- & --- & --- & --- & --- & --- & --- & --- \\
\hline Education & --- & --- & --- & --- & --- & --- & --- & --- & --- \\
\hline Prestige & --- & --- & --- & --- & --- & --- & --- & --- & --- \\
\hline Income & --- & --- & --- & --- & --- & --- & --- & --- & --- \\
\hline Self-employed & --- & --- & -- & --- & --- & --- & --- & --- & --- \\
\hline Silent Generation & --- & --- & --- & --- & --- & --- & --- & --- & --- \\
\hline Baby Boomers & --- & --- & --- & --- & --- & --- & --- & --- & --- \\
\hline Generation X & --- & --- & --- & -- & -- & --- & --- & --- & --- \\
\hline Generation Y & --- & --- & --- & --- & --- & --- & --- & --- & --- \\
\hline
\end{tabular}


Table 2 Cont.

\begin{tabular}{|c|c|c|c|c|c|c|c|c|c|}
\hline & Born U.S. & Education & Prestige & Income & $\begin{array}{c}\text { Self- } \\
\text { employed }\end{array}$ & $\begin{array}{c}\text { Silent } \\
\text { Generation }\end{array}$ & $\begin{array}{c}\text { Baby } \\
\text { Boomers }\end{array}$ & $\begin{array}{c}\text { Generation } \\
\mathrm{X}\end{array}$ & $\begin{array}{c}\text { Generation } \\
\mathrm{Y}\end{array}$ \\
\hline Feelings about Asians & .044 & $-.184 * *$ & $-.135^{* *}$ & $-.080 * *$ & $.055^{*}$ & .026 & .018 & $-.063^{* *}$ & $-.053 *$ \\
\hline Feelings about Hispanics & $.089^{* *}$ & $-.153^{* *}$ & $-.101^{* *}$ & $-.065^{* *}$ & .040 & .019 & .002 & $-.073^{* *}$ & -.026 \\
\hline Feelings about Blacks & .041 & $-.155^{* *}$ & $-.106 * *$ & $-.055^{*}$ & $.048^{*}$ & .022 & -.005 & -.045 & $-.057^{*}$ \\
\hline Male & -.016 & -.026 & -.017 & .012 & .037 & .003 & -.032 & .015 & .007 \\
\hline Midwest & -.030 & .027 & .034 & .031 & -.024 & .000 & .013 & -.008 & -.020 \\
\hline West & $-.138 * *$ & $.051^{*}$ & .021 & .000 & $.049 *$ & -.012 & -.035 & .025 & .001 \\
\hline Northeast & $.103^{* *}$ & -.044 & $-.095^{* *}$ & -.024 & $-.053^{*}$ & -.014 & -.023 & -.007 & $.091^{* *}$ \\
\hline Republican & $.053^{*}$ & $.105^{* *}$ & $.080^{* *}$ & $.135^{* *}$ & $.078^{* *}$ & $.049^{*}$ & .033 & -.024 & $-.068^{* *}$ \\
\hline Protestant & $.119 * *$ & -.044 & -.006 & -.039 & $.046^{*}$ & $.059^{*}$ & .021 & $-.085 * *$ & $-.093 * *$ \\
\hline Born U.S. & 1.000 & .021 & .015 & .018 & -.007 & .023 & .012 & $-.072 * *$ & .022 \\
\hline Education & -- & 1.000 & $.495^{* *}$ & $.345^{* *}$ & $.047^{*}$ & -.004 & $.078^{* *}$ & $.061^{* *}$ & $-.060^{* *}$ \\
\hline Prestige & --- & --- & 1.000 & $.312^{* *}$ & .037 & .016 & $.073^{* *}$ & .020 & $-.170^{* *}$ \\
\hline Income & --- & --- & -- & 1.000 & $.092 * *$ & .019 & $.217 * *$ & .019 & $-.172 * *$ \\
\hline Self-employed & --- & --- & --- & -- & 1.000 & -.002 & $.109^{* *}$ & $-.058^{*}$ & $-.111 * *$ \\
\hline Silent Generation & --- & --- & --- & --- & --- & 1.000 & $-.285^{* *}$ & $-.198 * *$ & $-.136^{* *}$ \\
\hline Baby Boomers & --- & --- & --- & --- & --- & -- & 1.000 & $-.441 * *$ & $-.303 * *$ \\
\hline Generation X & --- & --- & --- & --- & --- & --- & --- & 1.000 & $-.211 * *$ \\
\hline Generation Y & --- & --- & --- & --- & --- & --- & --- & --- & 1.000 \\
\hline
\end{tabular}

*pd.05 **pd.01 ***pd.001 
TABLE 3

Estimates of OLS Regression Models Predicting Whites' Feelings toward Asians, Hispanics, and Blacks, 2002 GSS

(Standard Errors in Parentheses)

\begin{tabular}{|c|c|c|c|c|c|c|}
\hline \multirow[b]{2}{*}{ Predictor } & \multicolumn{2}{|c|}{ Asians } & \multicolumn{2}{|c|}{ Hispanics } & \multicolumn{2}{|c|}{ Blacks } \\
\hline & B & $\beta$ & B & $\beta$ & B & $\beta$ \\
\hline Constant & $\begin{array}{l}5.418 * * * \\
(.313)\end{array}$ & & $\begin{array}{l}4.682 * * * * \\
(.322)\end{array}$ & & $\begin{array}{l}4.953 * * * \\
(.312)\end{array}$ & \\
\hline Education & $\begin{array}{l}-.089 * * * \\
(.018)\end{array}$ & -.132 & $\begin{array}{l}-.078 * * * \\
(.019)\end{array}$ & -.112 & $\begin{array}{l}-.079 * * * \\
(.018)\end{array}$ & -.117 \\
\hline Occupational Prestige & $\begin{array}{l}-.011 * * \\
(.004)\end{array}$ & -.079 & $\begin{aligned}-.008^{*} \\
(.004)\end{aligned}$ & -.054 & $\begin{aligned}-.009 * \\
(.004)\end{aligned}$ & -.064 \\
\hline Family income & $\begin{array}{l}-.008 \\
(.010)\end{array}$ & -.021 & $\begin{array}{l}-.005 \\
(.010)\end{array}$ & -.011 & $\begin{array}{c}-.001 \\
(.010)\end{array}$ & -.003 \\
\hline Self-employed & $\begin{array}{l}.307 * \\
(.137)\end{array}$ & .051 & $\begin{array}{l}.221 \\
(.142)\end{array}$ & .036 & $\begin{array}{l}.229 \\
(.137)\end{array}$ & .038 \\
\hline Male & $\begin{array}{l}.380 * * * \\
(.089)\end{array}$ & .097 & $\begin{array}{l}.433 * * * \\
(.091)\end{array}$ & .107 & $\begin{array}{l}.598 * * * \\
(.088)\end{array}$ & .153 \\
\hline \multicolumn{7}{|l|}{ Region $($ ref.=South) } \\
\hline Northeast & $\begin{array}{r}-.241 * \\
(.118)\end{array}$ & -.055 & $\begin{array}{r}-.305^{*} \\
(.121)\end{array}$ & -.067 & $\begin{array}{l}-.264 * \\
(.117)\end{array}$ & -.060 \\
\hline Midwest & $\begin{array}{c}-.071 \\
(.131)\end{array}$ & -.014 & $\begin{array}{l}.088 \\
(.135)\end{array}$ & .018 & $\begin{array}{l}.054 \\
(.131)\end{array}$ & .011 \\
\hline West & $\begin{array}{l}-.407 * * * \\
(.128)\end{array}$ & -.085 & $\begin{array}{l}-.446 * * * \\
(.131)\end{array}$ & -.091 & $\begin{array}{l}-.306^{*} \\
(.127)\end{array}$ & -.064 \\
\hline Republican & $\begin{array}{l}-.006 \\
(.097)\end{array}$ & -.001 & $\begin{array}{l}.052 \\
(.100)\end{array}$ & .012 & $\begin{array}{c}.097 \\
(.097)\end{array}$ & .023 \\
\hline Protestant & $\begin{array}{l}.099 \\
(.095)\end{array}$ & .025 & $\begin{array}{l}.170 \\
(.098)\end{array}$ & .042 & $\begin{array}{c}.079 \\
(.095)\end{array}$ & .020 \\
\hline U.S. born & $\begin{array}{l}.290 \\
(.177)\end{array}$ & .038 & $\begin{array}{l}.626 * * * \\
(.182)\end{array}$ & .079 & $\begin{array}{l}.294 \\
(.177)\end{array}$ & .038 \\
\hline \multicolumn{7}{|l|}{$\begin{array}{l}\text { Generation (ref.= G.I. } \\
\text { Generation) }\end{array}$} \\
\hline Silent Gen. & $\begin{array}{l}-.143 \\
(.179)\end{array}$ & -.023 & $\begin{array}{l}-.293 \\
(.185)\end{array}$ & -.046 & $\begin{array}{l}-.280 \\
(.179)\end{array}$ & -.045 \\
\hline Baby Boomers & $\begin{array}{l}-.194 \\
(.144)\end{array}$ & -.048 & $\begin{array}{r}-.336^{*} \\
(.148)\end{array}$ & -.081 & $\begin{array}{r}-.367 * \\
(.144)\end{array}$ & -.091 \\
\hline Generation $\mathrm{X}$ & $\begin{array}{l}-.428 * * \\
(.155)\end{array}$ & -.093 & $\begin{array}{l}-.553 * * * \\
(.159)\end{array}$ & -.116 & $\begin{array}{l}-.485 * * \\
(.154)\end{array}$ & -.105 \\
\hline Generation Y & $\begin{array}{l}-.613 * * * \\
(.177)\end{array}$ & -.104 & $\begin{array}{l}-.527 * * \\
(.183)\end{array}$ & -.087 & $\begin{array}{l}-.706 * * * \\
(.177)\end{array}$ & -.120 \\
\hline $\mathbf{R}^{2}$ (ad justed) & .063 & & .062 & & .065 & \\
\hline $\mathbf{F}$ & $9.246 * * *$ & & $9.087 * * *$ & & $9.578 * * *$ & \\
\hline $\mathbf{N}$ & 1,851 & & 1,851 & & 1,851 & \\
\hline
\end{tabular}

$* \mathrm{p} \leq .05 * * \mathrm{p} \leq .01 * * * \mathrm{p} \leq .001$ (one-tailed test)

ics (4.682), coolest toward Asians (5.418), and somewhat in-between toward blacks (4.953). These suggest that whites maintained the least social distance with Hispanics, followed by blacks and Asians. Although the differences are relatively small, these results contradict our hypothesis about the least social distance of whites to Asians and the greatest social distance of whites to blacks.

The comparison of the means in Table 1 and the constants in Table 3 for all three groups (Figure 1) reveals that without controlling for the 
predictor variables, the differences between whites and the minority groups in the feelings scales were quite small; however, controlling for the predictors, the differences increased significantly, but the order remained the same.

\section{FigURE 1}

Comparisons of Means and Constants for the Three Dependent Variables

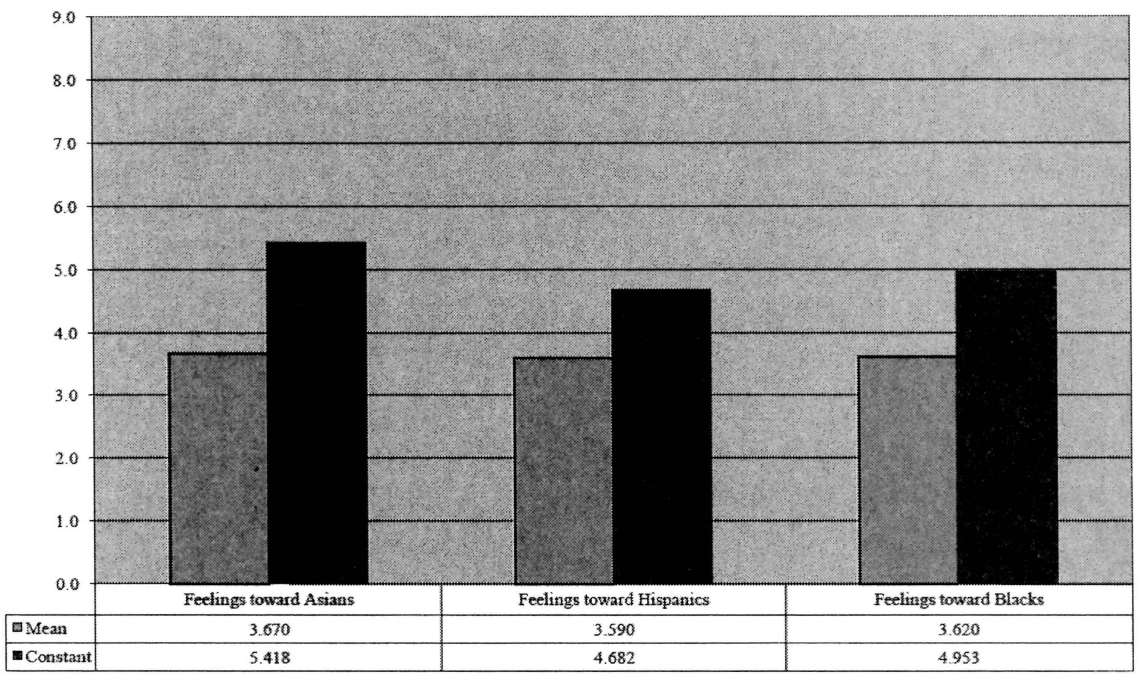

To answer our second research question, we turn to the specific regression coefficients in Table 3. As hypothesized, controlling for other variables, a higher level of education is negatively associated with cooler feelings of whites toward all three minority groups. Also anticipated, occupational prestige reduces the cooler feelings of whites toward all three minority groups, holding other variables constant. The effect of family income is in the expected direction but does not reach statistical significance at the .05 level. The effect of self-employment status is expectedly positive, but significant at the .05 level only for Asians.

Among the basic demographic variables, the effect of gender on the dependent variables is highly consistent with our hypotheses. White men tend to feel significantly cooler toward all three minorities than white women. Our hypothesis about regional differences is partially supported. Whites living in the West and the Northeast feel on average significantly warmer toward all three minorities than Southern whites, but whites living in the Midwest do not differ significantly from Southern whites in this regard.

We find no significant difference between white Republicans and white non-Republicans in feeling cool toward all three minority groups 
after holding other predictors constant. Nor do we detect a significant difference between white Protestants and white non-Protestants. Being born in the U.S. only significantly increases the cool feelings of whites toward Hispanics, but not toward blacks and Asians.

Coinciding with our hypothesis, the results indicate that the younger the generation, the warmer the feelings of whites toward minorities, although the differences between the Silent Generation and the G.I. Generation are not statistically significant at the .05 level for all three minority groups and the difference between the Baby Boomers and the G.I. Generation is also insignificant for Asians at the .05 level.

A comparison of standardized regression coefficients (â's) indicates that education is the most important predictor of feelings of whites towards all three minority groups. The effects of occupational prestige are also consistent across models.

\section{Discussion AND Conclusion}

The most important finding of this study is that in terms of whites' feeling toward minority groups, social distance is the smallest between whites and Hispanics, followed by between whites and blacks and finally by between whites and Asians. This finding contradicts our hypothesis about the least social distance of whites to Asians and the greatest social distance of whites to blacks. How do we explain this unexpected result? We offer several plausible explanations.

One possibility lies in the nativity of these particular minority groups. Because of different national cultures and social environments, the foreign-born are normally perceived as much more different from the natives, regardless of race or ethnicity, thereby leading to an increased social distance. The majority of Asians in the United States are foreignborn. According to the 2000 U.S. Population Census (U.S. Census Bureau 2003d), about 69 percent of all Asians were born outside the United States in that year. Asians are the only predominantly foreign-born group. Hence, this may largely explain the greatest social distance of whites to Asians. Nativity also explains the smaller social distance of whites to blacks, because an overwhelming majority of blacks are U.S. born and only about 6 percent of blacks were born abroad according to the 2000 U.S. Population Census (U.S. Census Bureau 2003d). However, nativity does not help in understanding why the social distance of whites to Hispanics is the smallest, since about 40 percent of Hispanic Americans are also foreign-born. Hence, other factors must also be at work.

Religious similarity or dissimilarity may partly explain the unpredicted finding. Most Hispanics, like whites, are Christians, including about 70 percent of Catholics (Schaefer 2010). Additionally, Hispanic Americans tend to shift away from Catholicism in favor of Protestantism 
(Hunt 1998). This religious similarity may in part account for the least social distance of whites to Hispanics. In contrast, the majority of Asians are non-Christians. This religious dissimilarity, therefore, increases their social distance from whites. The fact that a large majority of African Americans are Protestants-about 82 percent according to a 1990 national survey (Kosmin and Lachman 1993), largely Baptists and Methodists-partly explains the smaller social distance of whites to blacks.

Racial hierarchy and tension may partly explain why whites' social distance to blacks is in the middle. In terms of nativity and religious similarity, whites' social distance to blacks should be the smallest since the majority of blacks are native-born Protestants. Nevertheless, blacks rank low in the racial hierarchy and have greater tensions with whites. The outcome is an increased social distance between whites and blacks, although not to the extent of white-Asian social distance. This suggests that nativity and religious similarity play more important roles than racial hierarchy and tensions in social distances measured by feelings of closeness.

The geographic proximity of the country of origin might offer another explanation. Hispanics generally originate from countries less distant to the United States than Asians. As a result, whites may be more familiar with Hispanic cultural backgrounds than Asians'. Hence, proximity might help to explain why social distance between non-Hispanic whites and Hispanics is smaller than that between non-Hispanic whites and Asians.

The diversity of Asians might also help to understand the greatest social distance of whites to this particular group. In spite of whites' assumption of homogeny, Asians are very diverse (Wong et al. 1998). Asian groups "differ from each other in language, customs and culture, physical appearance and ... in the ways in which they have entered American society" (Healey 2004: 189). Asians also do not share a common religious or political orientation. In addition, Asian groups differ greatly in their socioeconomic status. According to the 2000 Population Census (U.S. Census Bureau 2003a, 2003b, 2005), Asian Indians fared the best in terms of major socioeconomic indicators, even better than whites, while Cambodians and Laotians fared the worst, even worse than Native Americans and Hispanics. Hispanic groups also do not think of themselves as one entity, and their diversity cannot be overlooked (Healey 2004). However, they still retain more common characteristics than Asians, such as religion, language, cultural traits, and with the exception of Cubans, also socioeconomic status. These common characteristics might contribute to the smaller social distance of whites to Hispanics. The devastation of African ethnic cultures by slavery and the racialization of Africans into a homogeneous group in the United States may also 
bring to light why white-black social distance is smaller than whiteAsian one.

The unexpected finding about the relative social distances between whites and the three major minority groups has important implications for race and ethnic relations today. The finding suggests that social distance in particular, and race and ethnic relations in general, are more complicated than what people normally believe. It may or may not be true to claim that white-black social distance is the greatest, depending on how social distance is measured. In terms of residential segregation and intermarriage, this claim may have merit. However, in terms of feelings of closeness it may be invalid. In fact, Asian Americans may be the most alienated, perhaps because of their "perpetual foreigner" image. The common experiences among many Asian Americans, and especially Asian immigrants, of being sidelined, ignored, and unrecognized or under-recognized in their daily life may vindicate the finding of the greatest social distance of whites to Asians. It may also be problematic to assert that African Americans are at the bottom of the racial and ethnic hierarchy today in terms of major socioeconomic indicators and political power. In fact, Native Americans and Hispanics, on average, fare worse according to recent census data on socioeconomic indicators and political representation.

Our findings also suggest that social distance cannot be explained by any single characteristic. For example, if color alone were to determine social distance, the greatest social distance would exist between whites and blacks. If alienation were the only determinant, we would also find the greatest social distance between whites and blacks. If social distance were based entirely on socioeconomic status or group image, then the analysis would show the smallest social distance between whites and Asians. In fact, none of these occurs. Thus, multiple determinants must be considered to fully understand social distance.

This study also reveals that whites with a higher socioeconomic status are in general more likely to maintain a smaller social distance to the three minority groups. In particular, whites with a higher level of education and a higher occupational prestige score tend to maintain a smaller social distance to the minorities than whites with a lower level of education and a lower prestige score. Family income works in the same direction, but does not attain statistical significance after controlling for other variables. These results suggest that increasing socioeconomic status is a way to reduce social distance between whites and minorities.

We also find that consistently white men tend to maintain a greater social distance to all three minority groups than white women. Whites living in the West and the Northeast tend to keep a smaller social distance to all three minority groups than Southern whites, but there is no 
significant difference in social distances to minorities between whites in the Midwest and Southern whites. On the other hand, being Republican or being Protestant does not make a significant difference in social distances of whites to minorities, respectively. Being native born increases whites' social distance to all three minority groups, but significantly only to Hispanics. Similarly, being self-employed significantly increases whites' social distance to Asians, but not to blacks or Hispanics. The results also reveal a general tendency that younger generations of whites are more likely to keep a smaller social distance to the minorities than older generations of whites, raising hopes of racial or ethnic integration and harmony for the future.

Future research may extend the current study along several lines. Keep in mind that feeling about minority groups used in our study is only one of the measures of social distance. If other measures of social distance are available, they should be used to further test our hypotheses. Future research should also incorporate other possible determinants of social distance, if possible. Furthermore, it is important to study changes in social distance between whites and minorities over time when longitudinal data become available.

\section{REFERENCES}

Alba, Richard, Ruben G. Rumbaut and Karen Marotz. 2005. "A Distorted Nation: Perceptions of Racial/Ethnic Group Sizes and Attitudes toward Immigrants and other Minorities." Social Forces 84(2): 901-920.

Beteille, Andre. 1990. "Race, Caste and Gender." Man 25(3): 489-504.

Blauner, Robert. 1972. Racial Oppression in America. New York: Harper \& Row.

Bobo, Lawrence D. and Vincent L. Hutchings. 1996. "Perceptions of Racial Group Competition: Extending Blumer's Theory of Group Position to a Multiracial Social Context." American Sociological Review 61(6): 951-972.

Bobo, Lawrence and James R. Kluegel. 1997. "Status, Ideology, and Dimensions of Whites' Racial Beliefs and Attitudes: Progress and Stagnation." Pp. 93-120 in Racial Attitudes in the 1990s: Continuity and Change, edited by Steven A. Tuch and Jack K. Martin. Westport, CT: Praeger Publishers.

Bobo, Lawrence, James R. Kluegel and Ryan A. Smith. 1997. "LaissezFaire Racism: The Crystallization of a Kinder, Gentler, Antiblack Ideology." Pp. 15-42 in Racial Attitudes in the 1990s: Continuity 
and Change, edited by Steven A. Tuch and Jack K. Martin. Westport, CT: Praeger Publishers.

Bogardus, Emory S. 1925. "Social Distance and Its Origins." Journal of Applied Sociology 9: 216-226.

Brink, William and Louis Harris. 1966. Black and White: A Study of U.S. Racial Attitudes Today. New York, NY: Simon and Schuster.

Campbell, Angus. 1971. White Attitudes Toward Black People. Ann Arbor, MI: Litho Crafters.

Emerson, Michael O., Karen J. Chai and George Yancey. 2001. "Does Race Matter in Residential Segregation? Exploring the Preferences of White Americans." American Sociological Review 66(6): 922935.

Feagin, Joe and Eileen O'Brien. 2004. White Men on Race: Power, Privilege, and the Shaping of Cultural Consciousness. Boston, MA: Bacon Press.

Firebaugh, Glenn and Kenneth E. Davis. 1988. "Trends in Antiblack Prejudice, 1972-1984: Region and

Cohort Effects." The American Journal of Sociology 94(2): 251-272.

Gans, Herbert. 1979. "Symbolic Ethnicity: The Future of Ethnic Groups and Culture in America." Ethnic and Racial Studies 2(2): 1-20.

Geschwender, James A. 1978. Racial Stratification in America. Dubuque, IA: William C. Brown Company Publishers.

Glazer, Nathan. 1993. "Is Assimilation Dead?" The Annals of the American Academy of Political and Social Science 530(1): 122-136.

Gordon, Milton M. 1964. Assimilation in American Life. New York: Oxford University Press.

Healey, Joseph F. 2004. Diversity and Society: Race, Ethnicity and Gender. Thousand Oaks, CA: Pine Forge Press.

Herring, Cedric and Charles Amissah. 1997. "Advance and Retreat: Racially Based Attitudes and Public Policy." Pp. 121-143 in Racial Attitudes in the 1990s: Continuity and Change, edited by Steven A. Tuch and Jack K. Martin. Westport, CT: Praeger Publishers.

Hunt, Larry L. 1998. "The Spirit of Hispanic Protestantism in the United States: National Survey Comparisons of Catholics and NonCatholics." Social Science Quarterly 79(4): 828-845.

Jaynes, Gerald D. and Robin M. Williams, Jr. 2000. "Changes in White Racial Attitudes." Pp. 7-18 in Multiculturalism in the United States: Current Issues, Contemporary Voices, edited by Peter Kivisto and Georganne Rundblad. Thousands Oaks, CA: Pine Forge Press. 
Johnson, Monica K. and Margaret M. Marini. 1998. "Bridging the Racial Divide in the United States: The Effect of Gender." Social Psychology Quarterly 61(3): 247-58.

Jones, Sydney and Susannah Fox. 2009. Pew Internet and American Life Project: Generations Online in 2009. Retrieved August 13, 2011, from http://www.pewinternet.org/ /media//Files/Reports/2009/PIP_ Generations_2009.pdf.

Kosmin, Barry and Seymour Lachman. 1993. One Nation Under God. New York: Harmony Books.

Ladd, Everett C. 2002. "What Americans Think about Race and Ethnicity." Pp. 53-68 in Beyond the Color Line: New Perspectives on Race and Ethnicity in America, edited by Abigail Thernstrom and Stephen Thernstrom. Stanford, CA: Hoover Institution Press.

Massey, Douglas S. and Nancy A. Denton. 1987. "Trends in the Residential Segregation of Blacks, Hispanics, and Asians, 1970-1980." American Sociological Review 52(6): 802-825.

Massey, Douglas S. and Nancy A. Denton. 1993. American Apartheid: Segregation and the Making of the Underclass. Cambridge, MA: Harvard University Press.

Merton, Robert K. 1941. "Intermarriage and Social Structure: Fact and Theory."Psychiatry 4: 361-374.

Middleton, Russell. 1976. "Regional Differences in Prejudice." American Sociological Review 41(1): 94-117.

Nakanishi, Donald. 1991. "The Next Swing Vote? Asian Pacific Americans and California Politics." Pp. 25-54 in Racial and Ethnic Politics in California, edited by Bruce E. Cain, Michael B. Preston and Sandra Bass. Berkeley, CA: Institute of Governmental Studies.

Noel, Joseph R. 1971. "White Anti-black Prejudice in the United States." International Journal of Group Tension 1(1): 59-76.

Park, Robert. 1924. "The Concept of Social Distance as Applied to the Study of Racial Attitudes and Racial Relations." Journal of Applied Sociology 8: 339-344.

Park, Robert E. 1937. "The Race Relations Cycle in Hawaii." Pp. 188195 in Race and Culture, vol. 1 (1950), edited by Everett C. Hughes et al. Glencoe, IL: Free Press.

Patchen, Martin. 1999. Diversity and Unity: Relations between Racial and Ethnic Groups. Chicago: Nelson-Hall.

Schaefer, Richard T. 2010. Racial and Ethnic Groups. Upper Saddle River, NJ: Pearson Education. 
Schuman, Howard, Charlotte Steeh, Lawrence Bobo and Maria Krysan. 1997. Racial Attitudes in America: Trends and Interpretations. Cambridge, MA: Harvard University Press.

Steeh, Charlotte and Howard Schuman. 1992. "Young White Adults: Did Racial Attitudes Change in the 1980s?" The American Journal of Sociology 98(2): 340-367.

Takaki, Ronald. 1989. Strangers from a Different Shore: A History of Asian Americans. Boston, MA: Little, Brown.

Tuch, Steven A. and Jack K. Martin. 1997. "Regional Differences in Whites' Racial Policy Attitudes." Pp. 165-174 in Racial Attitudes in the 1990s: Continuity and Change, edited by Steven A. Tuch and Jack K. Martin. Westport, CT: Praeger Publishers.

U.S. Census Bureau. 2003a. Educational Attainment: 2000, Census 2000 Brief. Retrieved July 22, 2011, from http://www.census.gov/prod/ 2003pubs/c2kbr-24.pdf.

U.S. Census Bureau. 2003b. Occupations: 2000, Census 2000 Brief. Retrieved July 22, 2011, from http://www.census.gov/prod/2003pubs/ c2kbr01-25.pdf.

U.S. Census Bureau. 2003c. Poverty: 1999, Census 2000 Brief. Retrieved July 22, 2011, from http://www.census.gov/prod/2003pubs/ c2kbr-19.pdf.

U.S. Census Bureau. 2003d. The Foreign Born Population 2000: Census 2000 Brief. Retrieved July 22, 2011, from http://www.census.gov/ prod/2003pubs/c2kbr-34.pdf.

U.S. Census Bureau. 2005. Household Income: 1999, Census 2000 Brief. Retrieved July 22, 2011, from http://www.census.gov/prod/2005 pubs/c2kbr-36.pdf.

Waters, Mary. 1990. Ethnic Options: Choosing Identities in America. Berkeley: University of California Press.

Weil, Frederick D. 1985. "The Variable Effects of Education on Liberal Attitudes: A Comparative-Historical Analysis of Anti-Semitism Using Public Opinion Survey Data." American Sociological Review 50(4): 458-474.

Wilson, Thomas C. 1996. "Cohort and Prejudice: Whites' Attitudes toward Blacks, Hispanics, Jews, and Asians." Public Opinion Quarterly 60(2): 253-274.

Wong, Paul, Chienping F. Lai, Richard Nagasawa and Tieming Lin. 1998. "Asian Americans as a Model Minority: Self-Perceptions and Perceptions by Other Racial Groups." Sociological Perspectives 41(1): 95-118. 
Yancey, George A. 1999. "An Examination of the Effects of Residential and Church Integration on Racial Attitudes of Whites." Sociological Perspectives 42(2): 279-304.

Yancey, George A. 2003. Who is White?: Latinos, Asians, and the New Black/Non-black Divide. Boulder, CO: Lynne Rienner Publishers.

Yang, Philip Q. 2000. Ethnic Studies: Issues and Approaches. Albany, NY: SUNY Press. 